\title{
Nonhost Resistance of Rice to Rust Pathogens
}

\author{
Michael Ayliffe, ${ }^{1}$ Rosangela Devilla, ${ }^{1}$ Rohit Mago, ${ }^{1}$ Rosemary White, ${ }^{1}$ Mark Talbot, ${ }^{1}$ Anthony Pryor, ${ }^{1}$ and \\ Hei Leung ${ }^{2}$ \\ ${ }^{1}$ CSIRO Plant Industry, Box1600, Canberra, ACT, 2601, Australia; ${ }^{2}$ International Rice Research Institute, DAPO Box 7777 , \\ Manila, Philippines
}

Submitted 20 April 2011. Accepted 26 June 2011.

\begin{abstract}
Rice is atypical in that it is an agricultural cereal that is immune to fungal rust diseases. This report demonstrates that several cereal rust species (Puccinia graminis f. sp tritici, $P$. triticina, $P$. striiformis, and $P$. hordei) can infect rice and produce all the infection structures necessary for plant colonization, including specialized feeding cells (haustoria). Some rust infection sites are remarkably large and many plant cells are colonized, suggesting that nutrient uptake occurs to support this growth. Rice responds with an active, nonhost resistance (NHR) response that prevents fungal sporulation and that involves callose deposition, production of reactive oxygen species, and, occasionally, cell death. Genetic variation for the efficacy of NHR to wheat stem rust and wheat leaf rust was observed. Unlike cereal rusts, the rust pathogen (Melampsora lini) of the dicotyledenous plant flax (Linum usitatissimum) rarely successfully infects rice due to an apparent inability to recognize hostderived signals. Morphologically abnormal infection structures are produced and appressorial-like structures often don't coincide with stomata. These data suggest that basic compatibility is an important determinate of nonhost infection outcomes of rust diseases on cereals, with cereal rusts being more capable of infecting a cereal nonhost species compared with rust species that are adapted for dicot hosts.
\end{abstract}

Fungal rust diseases caused by members of the genus Puccinia consistently cause yield losses and occasional devastating epidemics in the world's most important crops, cereals (Roelfs and Bushnell 1985). Most cereal rust disease resistance genes have transient efficacy due to pathogen mutations overcoming resistance. The emergence of Ug99, a new pathotype of wheat stem rust (WSR) (Puccinia graminis f. $\mathrm{sp}$ tritici) that threatens global wheat production, emphasizes the need for durable rust resistance in cereals (Ayliffe et al. 2008; Stokstad 2007).

Rice (Oryza sativa) is atypical in that it is an intensively grown agricultural cereal that is a nonhost of rust pathogens, unlike wheat, barley, maize, rye, triticale, millet, oat and sorghum, which are all hosts. Nonhost resistance (NHR) is a poorly characterized defense mechanism that makes a plant species resistant to most potential phytopathogens (i.e., a nonhost). The genetic elucidation of NHR components in Arabidopsis demonstrates that NHR is not as intractable as previously regarded (Collins et al. 2003; Lipka et al. 2005; Stein et

Corresponding author: Michael Ayliffe; E-mail: michael.ayliffe @csiro.au

* The $e$-Xtra logo stands for "electronic extra" and indicates that supplementary data is published online. al. 2006). The potential transfer of rice nonhost rust resistance to other cereals is attractive (Borlaug 2000) given the apparent durability of NHR, extensive rice genomic resources available, and an example of successful transfer of NHR between cereals (Zhao et al. 2005).

The current model of plant NHR (Jones and Dangl 2006) suggests that all microbes possess a suite of conserved molecules, called microbe- and pathogen-associated molecular patterns (MAMPs and PAMPs, respectively) that can be recognized by plants, often via a receptor kinase located in the plant plasma membrane (Zipfel 2008). This recognition (PAMP-triggered immunity) evokes activation of an NHR response or basal defense response that prevents further infection of the plant by nonadapted pathogen species (Zipfel 2008). In contrast, adapted pathogens suppress PAMP-triggered immunity by introducing a suite of pathogen molecules (effectors) into the infected plant cell that suppress this basal defense response (Hogenhout et al. 2009). Host plant species, in turn, have evolved recognition mechanisms for specific effector molecules of adapted pathogens leading to effector-triggered immunity, which is the underlying molecular basis of the gene-forgene model of disease resistance (Jones and Dangl 2006). However, effector-triggered immunity is not just confined to adapted pathogen recognition and may also play a role in NHR, particularly against pathogens that colonize plant species closely related to the nonhost species (Schulze-Lefert and Pangstruga 2011).

Therefore, NHR involves active recognition and an induced defense response in some instances. However, NHR defenses also include preformed physical and chemical barriers that potential pathogens must overcome for successful plant colonization (Heath 2000). Superimposed on these active and passive defense mechanisms is a pathogen requirement for appropriate plant signals, both physical and chemical, for pathogen recognition of a potential plant host (Heath 2000).

Several studies have investigated the attempted infection of rust pathogens on nonhost plant species. Mellersch and Heath (2003) examined the infection process of bean rust (Uromyces vignae) on the nonhost plant species, Arabidopsis. Of 17 Arabidopsis accessions examined, 1 (WS-0) allowed significantly more rust growth, with $20 \%$ of infection sites each producing a few haustoria. The remaining accessions generally restricted fungal growth after the formation of short infection hyphae within the apoplast. Arabidopsis mutants (edsl and $n d r l)$ which are defective for signaling pathways essential for nucleotide-binding site leucine-rich repeat (NBS-LRR) resistance gene function did not show increased rust growth, suggesting that these effector recognition pathways are either not involved in the NHR of Arabidopsis to this nonadapted pathogen or are redundant due to alternative resistance mechanisms. In contrast, Arabidopsis plants deficient in salicylic acid (SA) 
signaling (sid2) or encoding a salicylate hydroxylase transgene $(N a h G)$ allowed increased Uromyces infection prior to the fungus being stopped by other components of NHR.

When Arabidopsis was challenged with a second nonadapted pathogen, $P$. triticina, the causative agent of wheat leaf rust (WLR), poor infection of the nonhost plant was observed by this cereal pathogen (Shafiei et al. 2007). Only 12\% of germinated spores successfully located a stomate and just $0.2 \%$ of infection sites produced a haustorium within a mesophyll cell (Shafiei et al. 2007). Attempted infection by $P$. triticina induced the production of reactive oxygen intermediates, nitric oxide, SA, and camalexin. Arabidopsis mutants deficient for a range of defense-signaling pathway genes, including $R A R l$ and EDS1, showed no increased colonization by the nonadapted pathogen compared with control lines (Shafiei et al. 2007).

Most but not all barley accessions are immune to WLR $(P$. triticina) and several other fungal rust species (e.g., $P$. hordeimurini, $P$. hordei-secalini, and $P$. coronata f. sp avenae) (Atienza et al. 2004). In an analysis of this "near-NHR", mapping families were produced between immune and rare susceptible parents (Jafary et al. 2008). Resistance to these rust pathogens was shown to be polygenically inherited, with substantial overlap between quantitative trait loci (QTL) for resistance to each rust species. Interestingly, a number of these same QTL coincided with QTL for partial resistance to the adapted barley leaf rust pathogen $P$. hordei. No association with known barley leaf rust resistance $(R)$ genes was observed (Jafary et al. 2008).

In spite of the unique immunity among cereals of rice to cereal rusts, an investigation of the ability of rust pathogens to infect rice has not been reported. In this study, we have developed a simple histochemical staining procedure to demonstrate that cereal rust pathogens can infect rice and, in some cases, produce very large, haustoria-containing infection sites that encompass many host mesophyll cells. Natural variation among rice cultivars in the NHR response to wheat stem and leaf rust was observed. No increased rust growth was observed on rice plants that had either lost basal resistance to an adapted rice pathogen (Magnaporthe grisea) or were deficient for several defense-related genes. These data suggest that rice has substantial redundancy in NHR mechanisms to cereal rusts. In contrast to the extensive cereal rust growth observed at some infection sites on rice, flax rust (Melampsora lini), the rust pathogen of the dicotledenous plant flax (Linum ussitatissimum), rarely successfully infects this monocot nonhost species.
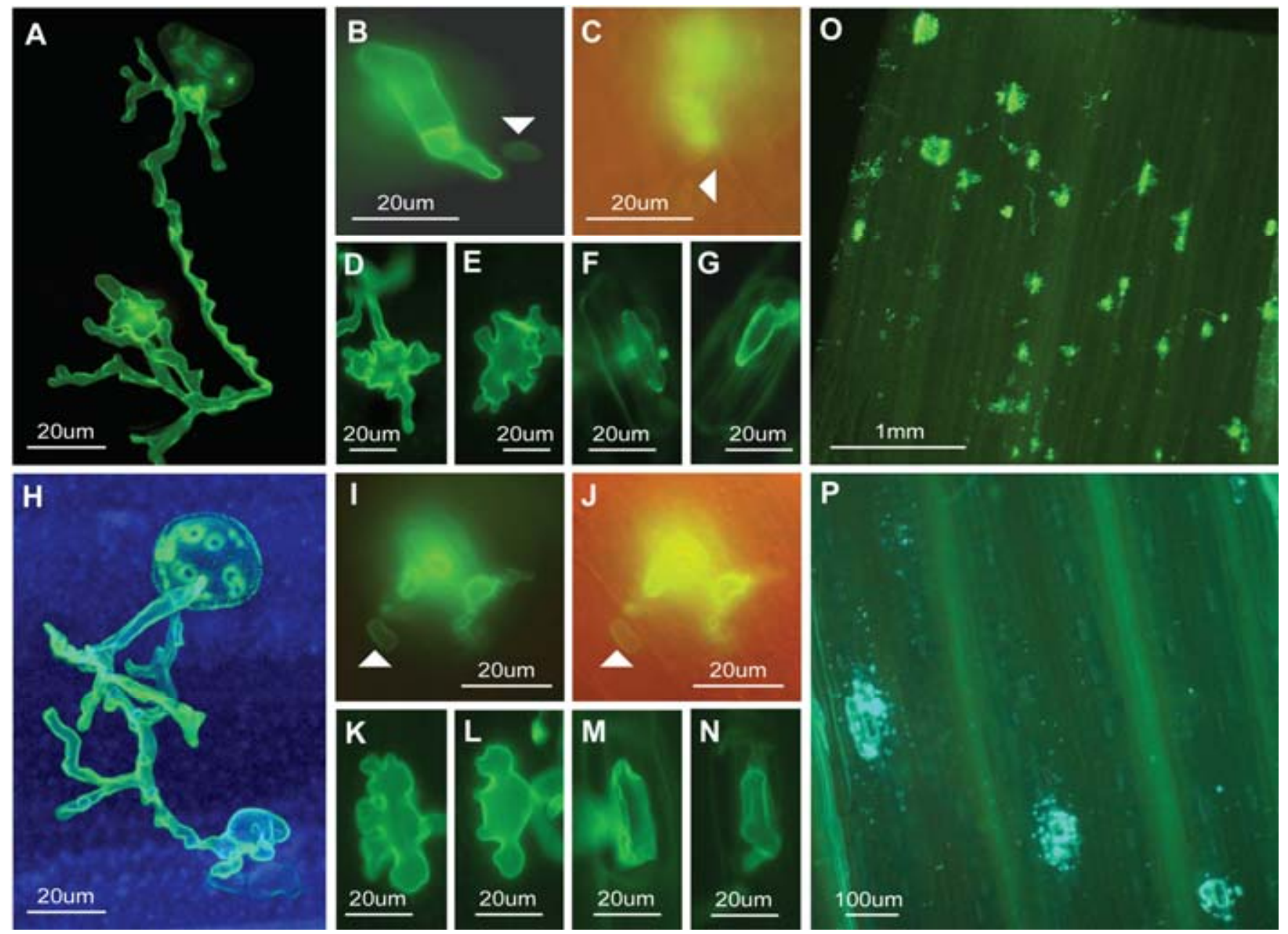

Fig. 1. Infection of rice with Puccinia graminis isolate 21-0 and $P$. hordei. A, Germinated P. graminis spore on the surface of a rice leaf showing germ tube and appressorium development. B, P. graminis substomatal vesicle, infection hyphae, and haustorium formation inside a rice leaf. $\mathbf{C}, P$. graminis haustorium located in a rice leaf mesophyll cell. D and E, Two $P$. graminis appressoria growing on rice leaves. Note altered morphology when compared with F and G. F and $\mathbf{G}, P$. graminis appressorium development on wheat stomata. $\mathbf{H}$, Confocal microscopy showing infection structures of a $P$. horde $i$ infection site on rice. The spore, germ tube, and appressorium are present on the surface of the leaf, while the underlying substomatal vesicle is inside the leaf and seen as a paler structure at the bottom right of the panel. I, Haustorium produced by a $P$. hordei infection site on rice. J, The same infection site shown in I, demonstrating the epidermal cell location of the $P$. hordei haustorium. $\mathbf{K}$ and $\mathbf{L}$, Morphology of $P$. hordei appressoria on rice leaves. $\mathbf{M}$ and $\mathbf{N}$, Morphology of $P$. hordei appressoria on barley leaves. O, Variation in $P$. horde $i$ infection site sizes observed on a single rice leaf. $\mathbf{P}$, Callose production associated with $P$. horde $i$ infection sites on a rice leaf. In B, C, I, and J, white arrowheads indicate the position of haustoria. 


\section{RESULTS}

Infection of rice by four species of cereal rusts.

Three rice cultivars ('IR64', 'Kyeema,' and 'Namaga') were inoculated with $P$. graminis f. sp tritici race 21-0, the causal agent of WSR, and microscopically assayed after staining with wheat germ agglutinin-alexa 488 (WGA-alexa). Of the 331 spore germination events examined on these three cultivars, on average, 55\% successfully produced appressoria (Fig. 1A) while the remaining $45 \%$ produced only germ tubes (Table 1). On wheat 'Morocco', which is susceptible to this stem rust isolate, $80 \%$ of WSR spore germination events generated appressoria (Table 1).

Similar results were observed when rice was infected with $P$. hordei, the causal agent of barley leaf rust (BLR). Analysis of 585 BLR spore germination events on seven rice cultivars showed that, on average, $46 \%$ of germinated spores successfully produced an appressorium over a stomate (Fig. 1H; Table $1)$. The remaining spore germination events $(54 \%)$ produced a germ tube that did not produce an appressorium. When the same BLR race was used to infect the susceptible host species, 'Golden Promise' barley, 79\% of germinated spores successfully went on to produce appressoria (Table 1).

Of those BLR infection sites on rice that successfully produced appressoria, 93\% subsequently went on to produce substomatal vesicles and infection hyphae (Fig. 1H; Table 2), while $79 \%$ of WSR appressoria produced on rice gave rise, in turn, to substomatal vesicles and infection hyphae (Fig. 1B; Table 2). When these rusts were inoculated onto susceptible host species, $98 \%$ of barley leaf rust appressoria produced infection hyphae on barley, as did $99 \%$ of WSR appressoria on wheat.

These initial infection processes can be summarized as follows. Of the BLR spores that germinate on the susceptible barley Golden Promise, 77\% successfully produce infection hyphae
$(79 \times 98 \%)$, while $79 \%(80 \times 99 \%)$ of germinated WSR spores produced infection hyphae on the susceptible wheat Morocco. In contrast, when these two cereal rusts were inoculated onto a number of different rice cultivars, on average, $43 \%$ of BLR $(46 \times 93 \%)$ and $43 \%$ of WSR $(55 \times 79 \%)$ spores that germinated successfully produced infection hyphae.

Obvious alteration in the appressorium morphology of BLR was observed when grown on rice compared with the barley host, with appressoria appearing more bulbous and lobed (Fig. $1 \mathrm{~K}$ to N). Similar morphological differences were observed when WSR was grown on rice compared with wheat, with more bulbous appressoria again observed (Fig. 1D to G). However, these bulbous appressoria did subsequently produce infection hyphae and haustoria (Fig. 1B, C, I, and J). The frequency of haustorium production was not quantified due to difficulty in their routine identification.

Some BLR and, particularly, WSR infection sites became very large and encompassed hundreds of mesophyll cells (Fig. 2). The size of these infection sites and the presence of haustoria suggest that direct nutrient uptake from this nonhost species tissue is occurring because the energy reserves of a single spore are unlikely to sustain such extensive growth. Considerable variation in infection site sizes of both rusts was observed, even on the same leaf, suggesting a dynamic but relatively stochastic interaction occurring between rice and these nonadapted cereal rust pathogens (Fig. 10). Within the same leaf, infections that progressed beyond the substomatal vesicle stage varied from those that formed only one or two short infection hyphae with no haustoria to those with a very large proliferation of infection hyphae with haustoria (Figs. 10 and 2).

Coupled with the apparent stochastic development of these two cereal rust species on rice were clear environmental effects on nonadapted pathogen development. Significant differences

Table 1. Percentage of germinated rust spores that produce appressoria on rice compared with host species

\begin{tabular}{llccr}
\hline Cultivar, plant & \multicolumn{1}{c}{ Rust $^{\mathbf{a}}$} & $\begin{array}{c}\text { Spores producing germ tube only } \\
(\boldsymbol{\%})\end{array}$ & $\begin{array}{c}\text { Spores producing germ tube and } \\
\text { appressorium }(\boldsymbol{\%})\end{array}$ & $\begin{array}{c}\text { Number of germinated } \\
\text { spores examined }\end{array}$ \\
\hline IR64 rice & WSR 21-0 & 46 & 54 & 116 \\
Kyeema rice & WSR 21-0 & 52 & 48 & 99 \\
Namaga rice & WSR 21-0 & 38 & 62 & 116 \\
Morocco wheat & WSR 21-0 & 20 & 80 & 97 \\
IR64 rice & BLR & 58 & 42 & 69 \\
Purple rice & BLR & 79 & 21 & 114 \\
Wild rice & BLR & 39 & 61 & 90 \\
Pelde rice & BLR & 67 & 33 & 60 \\
Namaga rice & BLR & 20 & 80 & 97 \\
Amaroo rice & BLR & 57 & 43 & 81 \\
Koshihikara rice & BLR & 57 & 43 & 74 \\
Golden Promise barley & BLR & 21 & 79 & 172 \\
\hline
\end{tabular}

\footnotetext{
${ }^{\mathrm{a}} \mathrm{WSR}=$ wheat stem rust and BLR $=$ barley leaf rust.
}

Table 2. Percentage of rust infections that, upon forming an appressorium, subsequently produce only an appressorium (App.), an appressorium and substomatal vesicle (ssv), or an appressorium + ssv + infection hyphae (ifh) on rice and host species

\begin{tabular}{llcccc}
\hline Cultivar, plant & \multicolumn{1}{c}{ Rust $^{\mathbf{a}}$} & App. only (\%) & App. + ssv (\%) & App + ssv + ifh (\%) & Number of infection sites examined \\
\hline IR64 rice & BLR & 4 & 6.5 & 89.5 & 46 \\
YRM54 rice & BLR & 4.5 & 2 & 94.5 & 44 \\
Opus rice & BLR & 0 & 0 & 100 & 80 \\
Langi rice & BLR & 7.5 & 2.5 & 90 & 40 \\
Namaga rice & BLR & 0 & 1 & 89 & 76 \\
Amaroo rice & BLR & 4 & 9 & 91 & 55 \\
Koshihikara rice & BLR & 0 & 0 & 98 & 57 \\
Golden Promise barley & BLR & 2 & 0 & 83 & 71 \\
IR64 rice & WSR 21-0 & 17 & 0 & 75 & 27 \\
Kyeema rice & WSR 21-0 & 25 & 0 & 99 & 130 \\
Morocco wheat & WSR 21-0 & 1 & &
\end{tabular}

${ }^{\mathrm{a}} \mathrm{BLR}=$ barley leaf rust and WSR $=$ wheat stem rust. 
between medium infection site sizes were observed between replicate experiments, and longer infection times did not necessarily correlate with increase fungal development (described below), even though experiments were undertaken in climatecontrolled glasshouses. This experimental variation precludes direct quantitative comparisons between different experiments; however, qualitative observations were consistent.

Infection of rice with another three rust species- $P$. triticina (WLR), P. striiformis (wheat stripe rust), and P. sorghi (common maize rust) (not shown)_also produced a distribution of infection sites ranging from little more than substomatal vesicles to those that encompassed numerous mesophyll cells and produced haustoria (Fig. 2). At no stage did any rust species complete their asexual cycle by producing urediospores, and no evidence of the spore producing asexual reproductive structure, the uredium, was apparent. These data demonstrate that five different cereal rust species that are pathogens of Poaceae spp. can all infect rice plants and, in some instances, produce large infection sites that colonize hundreds of mesophyll cells prior to fungal growth being suppressed by an NHR response.

\section{Cytological evaluation of the rice NHR response to cereal rust infection.}

An active NHR response was shown to be involved in the suppression of cereal rust growth on rice. Aniline blue staining indicated that callose deposition was associated with rust infection sites (Fig. 1P), as was occasional plant cell autofluorescence, which is indicative of cell death (Fig. 3A to F). Staining with 3-3'diaminobenzidine (DAB) detected the production of hydrogen peroxide around rust infection sites, with larger infection sites showing greater zones of hydrogen peroxide production (Fig. 3G to J). Hydrogen peroxide production was not limited to infected mesophyll cells and stomatal guard cells also produced this reactive oxygen species in response to appressorium production or even to what appeared to be attempted appressorium production (Fig. 3K and L). Callose deposition and hydrogen peroxide production were commonly observed at rust infection sites whereas autofluorescence was uncommon, suggesting that most rust infections were prevented by mechanisms other than rice cell death that produced autofluorescence.
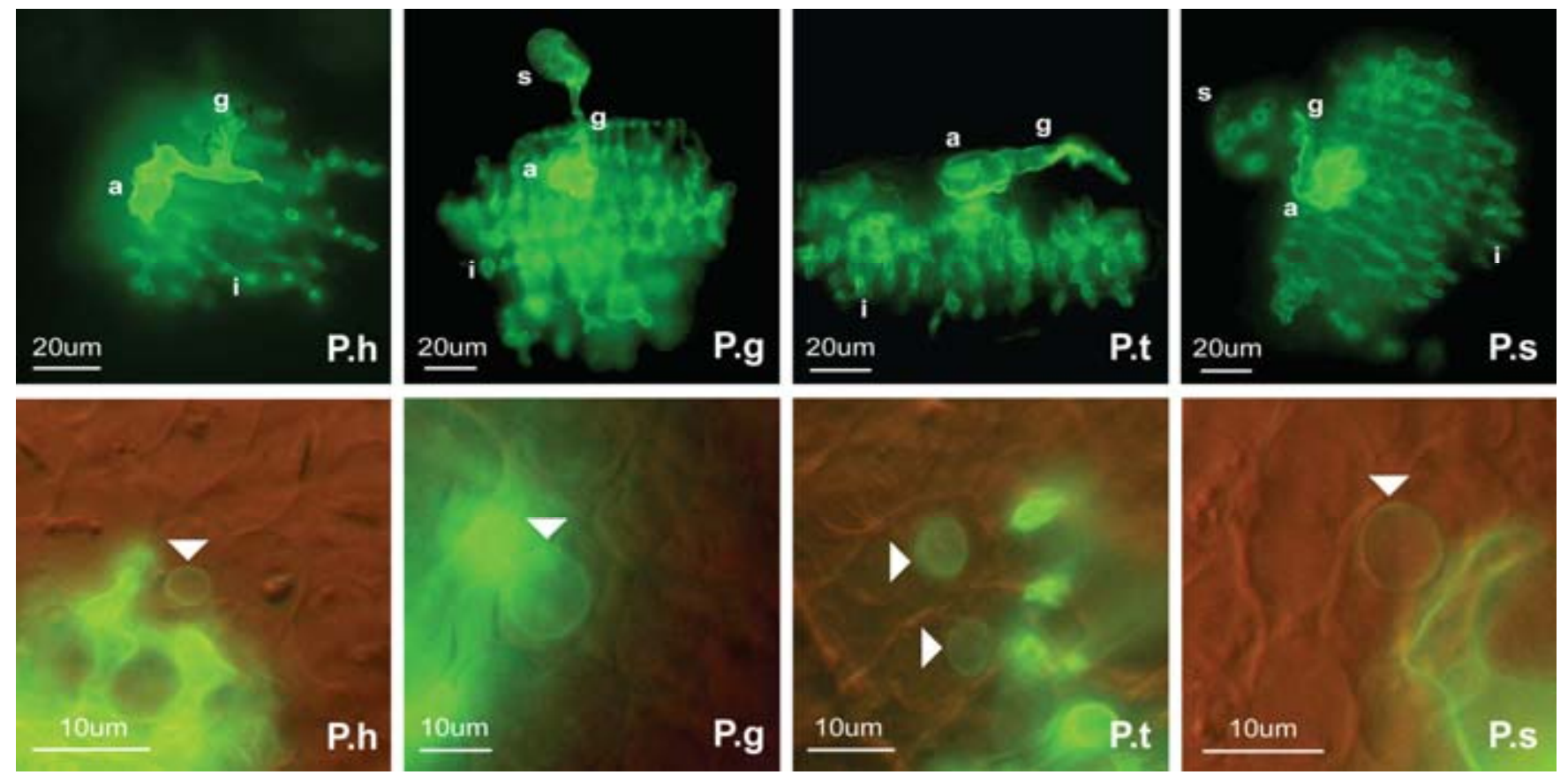

Fig. 2. Large, single cereal rust infection sites observed on rice. From left to right: rice infected with Puccinia hordei (P.h), P. graminis (P.g), P. triticina (P.t), and $P$. striiformis (P.s). Upper row shows extensive growth of infection hyphae (i) within the leaf, while spores (s), germ tubes (g), and appressoria (a) are present on the leaf surface. Lower row shows haustoria (marked with an arrowhead) present within rice mesophyll cells. Each image in the upper row is a composite of stacked photographs.

Fig. 3. A, Puccinia graminis appressorium on the surface of a rice leaf with underlying infection structures inside in the leaf visible in a different focal plane. B, Autofluorescent mesophyll cells associated with the . graminis infection site shown in A. C, $P$. hordei substomatal vesicle (ssv) and infection hyphae inside a rice leaf. D, Autofluorescent mesophyll cells associated with the $P$. hordei infection site shown in C. E, P. striiformis infection site showing extensive ramification of infection hyphae within a rice leaf. F, Autofluorescence of rice mesophyll cells at the $P$. striiformis infection site shown in E. G and $\mathbf{H}, 3$ 3'Diaminobenzidine (DAB) staining showing hydrogen peroxide production associated with $P$. graminis infection sites on rice leaves. I and $\mathbf{J}$, Hydrogen peroxide production associated with a $P$. horde $i$ infection site on a rice leaf. I shows wheat germ agglutinin-alexa 488 staining of the rust infection site while panel $\mathbf{J}$ shows localization of hydrogen peroxide around this same site by DAB staining. $\mathbf{K}$, Attempted appressorium formation of a $P$. hordei germ tube on the surface of a rice leaf. $\mathbf{L}$, Hydrogen peroxide formation in stomatal guard cells associated with the attempted $P$. hordei appressorium formation shown in K. M, Melampsora lini infection site growing on a flax leaf. The germinating spore, germ tube, and appressorium are evident on the surface of the leaf while underlying infection hyphae can be seen inside the leaf. $\mathbf{N}$, Germinated $M$. lini spore showing appressorium development on the surface of a flax leaf. $\mathbf{O}$, Appressorium development of $M$. lini on the surface of a rice leaf. $\mathbf{P}$ and $\mathbf{Q}$, Appressorium development of an $M$. lini infection site on rice that is not associated with a stomate. In Q, the arrow indicates the position of the nearest stomate. R, Two M. lini infection sites on rice. The upper infection site has produced an appressorium over a stomate (arrow), while the lower infection site has produced an aberrant appressorium-like infection structure that is not associated with a stomate. S and T, M. lini infection sites that have produced appressoria with additional hyphal-like extensions. Stomates are indicated in each panel with arrows. $\mathbf{U}$, Two $M$. lini infection sites on rice that produce aberrant appressoria-like structures that are not associated with stomata. $\mathbf{V}$, Two M. lini infection sites on rice. The upper spore has germinated to produce an appressorium with a short infection hyphae (indicated with a white arrow) that has entered the leaf. The lower infection site has produced an appressorium only. W, $M$. lini infection site showing a germinated spore that has produced an appressorium over a rice leaf stomate and short infection hyphae (indicated with a white arrow) within the leaf apoplast. 

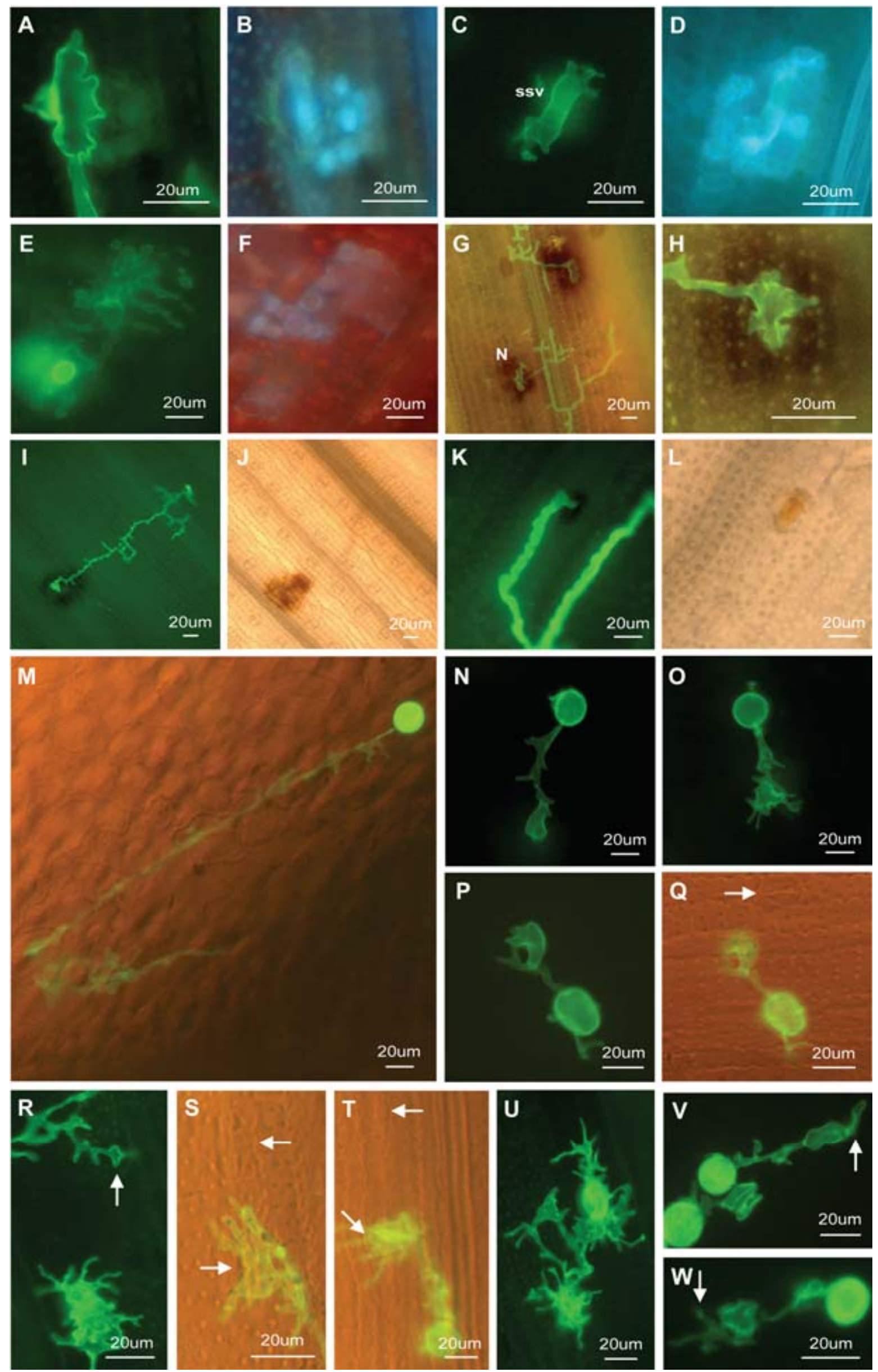

20um

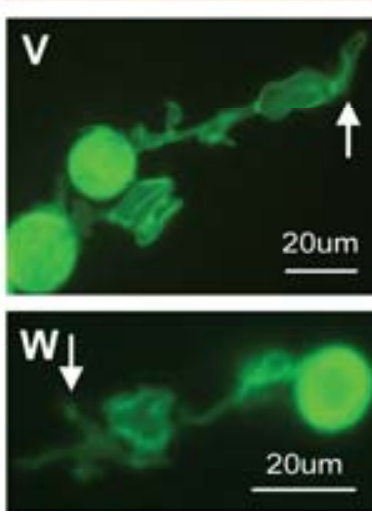

Vol. 24, No. 10, 2011 / 1147 
Namaga

IR64

Kyeema
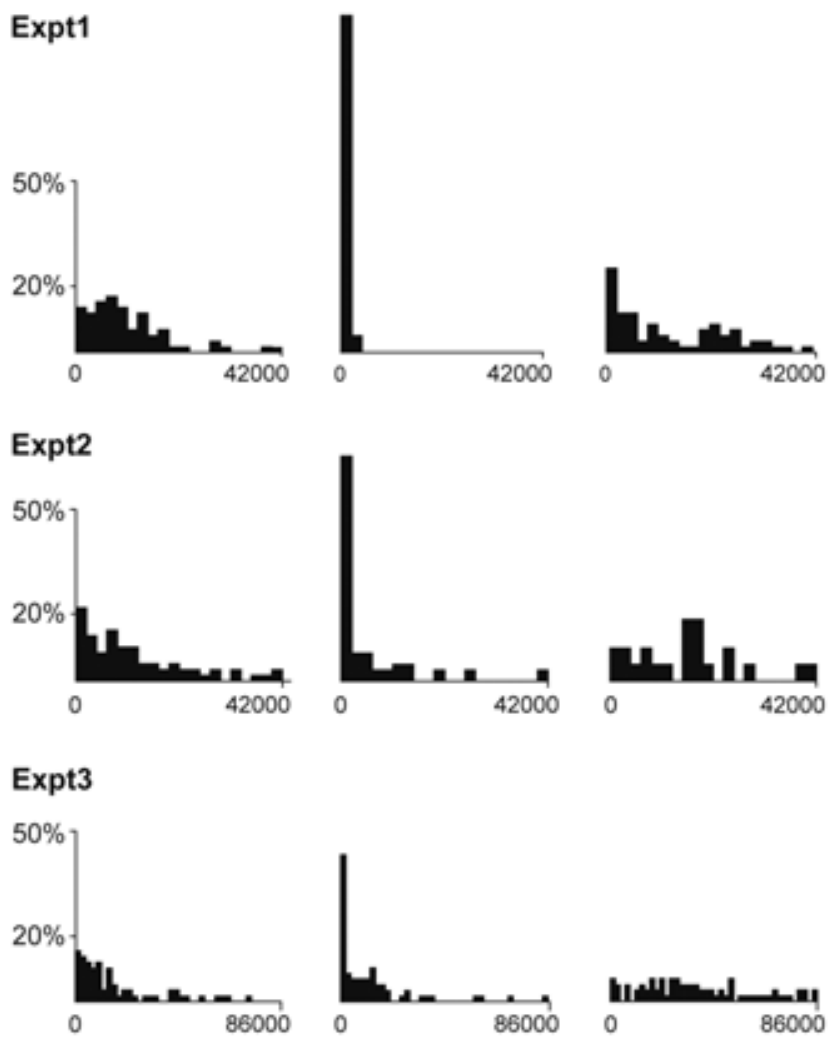

m

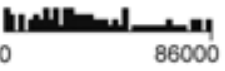

Expt4
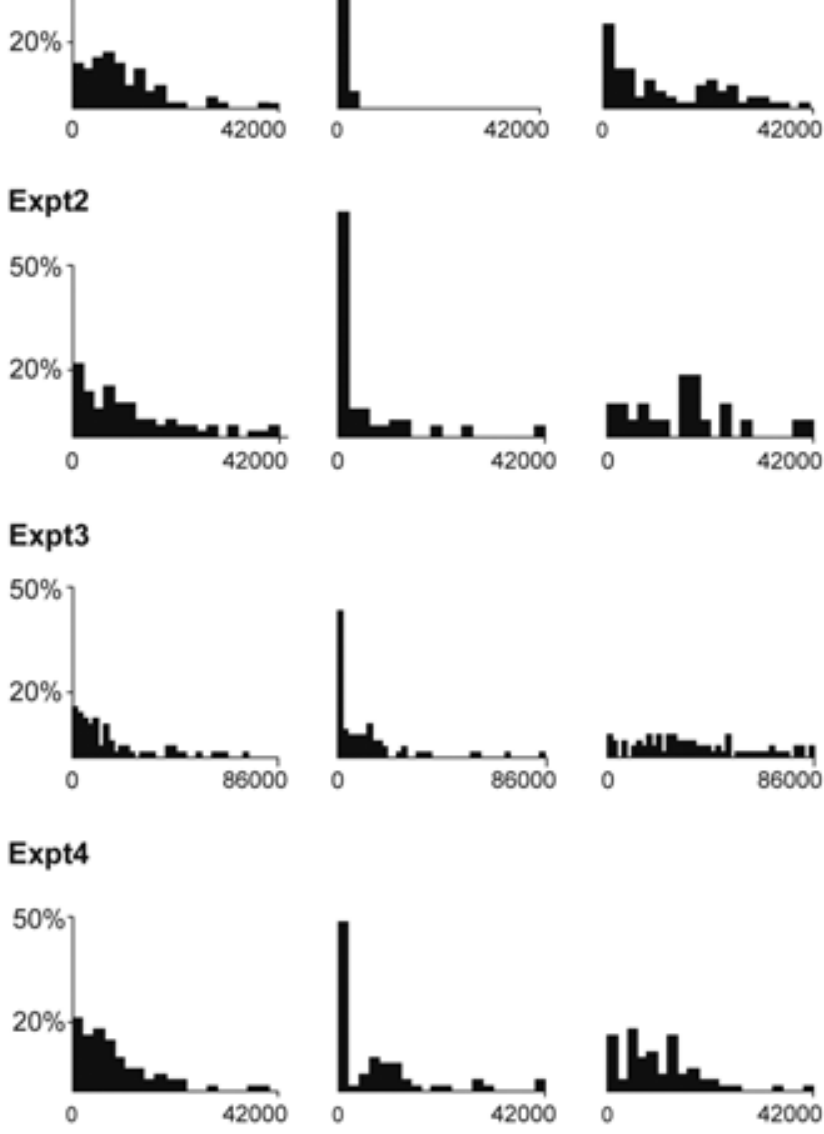

Fig. 4. Growth of wheat stem rust isolate 21-0 on 'Namaga', 'IR64', and 'Kyeema' rice. Nine separate graphs are shown that each depict that the distribution of infection site areas measured on a single rice cultivar. Each row of three graphs are the results from a single experiment while each column shows the distribution of infection site sizes observed for the same cultivar over each of four experiments. The $y$ axis on each graph indicates percent of infection sites while the $x$ axis indicates infection site area in square micrometers. Infection site sizes were measured for experiments 1 to 4 after $7,7,11$, and 16 days postinoculation, respectively.
Genetic variation of rice NHR to cereal rust.

To determine whether genetic variation may exist between rice cultivars for the efficacy of the NHR response to WSR, 12 different rice cultivars (listed below) were assessed in a preliminary, qualitative screen for differences in infection site areas. From this preliminary screen, two cultivars (Kyeema and Namaga) appeared to have, on average, larger rust infection sites compared with the remaining cultivars.

A quantitative analysis (described below) was undertaken on WSR infection site areas for Kyeema, Namaga, and IR64 rice. This latter cultivar was representative of the remaining rice cultivars that were all more restrictive of WSR growth and was chosen because of the availability of mutants of this line (described below). The areas of WGA-alexa-stained stem rust infection sites were measured over four replicate experiments using three different infection times (Fig. 4). Only those infection sites that produced infection hyphae were considered.

For all three cultivars, a spectrum of infection site sizes was observed that ranged from small (i.e., little more than a substomatal vesicle) to very large (i.e., encompassing hundreds of mesophyll cells). However, from these analyses, it was apparent that reproducible differences in infection site areas were observed. In general, most infection sites on IR64 were small in area, whereas the infection sites of Namaga and, particularly, Kyeema were frequently larger (Fig. 4). This infection site area distribution pattern was consistent for these three cultivars over the four experiments. Statistical analyses using Mann Whitney $\mathrm{U}$ tests indicated a highly significant difference $(P<0.01)$ in the distribution of infection site areas between all three cultivars in each experiment, except for Namaga and Kyeema in experiment 1 (Table 3). The differences in WSR growth on these three cultivars was also reflected in median infection site area values (Fig. 5A; Table 3).

Several observations are noteworthy in this dataset. First, large differences in individual infection site areas were observed on each rice cultivar, including IR64, the cultivar most restrictive of WSR growth. Second, the infection site areas obtained between experiments was variable and was not necessarily a function of infection time (Fig. 4, compare experiment 3 [11 days postinfection] and experiment 4 [16 days postinfection]). These two observations suggest that, in addition to genetic factors, environmental factors influence the growth of WSR on rice. Significant experimental variation in NHR to rust infection was also reported for the interaction between Arabidopsis and Uromyces spp. (Mellersch and Heath 2003). In spite of this interexperiment variation, the relative growth of WSR was consistently greatest on Kyeema, followed by Namaga and IR64.

Table 3. Comparison of wheat stem rust 21-0 (WSR) and wheat leaf rust (WLR) infection site areas on three rice cultivars

\begin{tabular}{|c|c|c|c|c|c|}
\hline Comparison & Rust & Experiment $1^{\mathrm{a}}$ & Expriment 2a & Expriment $3^{\text {a }}$ & Expriment $4^{a}$ \\
\hline Namaga vs. IR64 & WSR & $\begin{array}{l}3,948 \text { vs. } 65(91)(36) \\
P<0.0001\end{array}$ & $\begin{array}{l}3,443 \text { vs. } 496(95)(61) \\
P<0.0001\end{array}$ & $\begin{array}{l}4,144 \text { vs. } 2,240(101)(113) \\
P<0.007\end{array}$ & $\begin{array}{l}2,920 \text { vs. } 1,281(147)(75) \\
\quad P<0.0017\end{array}$ \\
\hline Kyeema vs. IR64 & WSR & $\begin{array}{l}4,353 \text { vs. } 55(71)(36) \\
P<0.0001\end{array}$ & $\begin{array}{l}7,435 \text { vs. } 496(23)(61) \\
P<0.0001\end{array}$ & $\begin{array}{l}15,623 \text { vs. } 2,240(117) \\
(113) P<0.0001\end{array}$ & $\begin{array}{l}4,394 \text { vs. } 1,281(73)(75) \\
P<0.0001\end{array}$ \\
\hline Kyeema vs. Namaga & WSR & $\begin{array}{c}4,353 \text { vs. } 3948(71)(91) \\
0.24<P<0.47\end{array}$ & $\begin{array}{l}7,435 \text { vs. } 3443(23)(95) \\
\quad P<0.01\end{array}$ & $\begin{array}{l}15,623 \text { vs. } 4,144(117) \\
\text { (101) } P<0.0001\end{array}$ & $\begin{array}{l}4,394 \text { vs. } 2,920(73)(147) \\
\quad P<0.0015\end{array}$ \\
\hline Namaga vs. IR64 & WLR & $\begin{array}{r}353 \text { vs. } 182(58)(84) \\
0.0005<P<0.001\end{array}$ & $\begin{aligned} 480 & \text { vs. } 195(37)(55) \\
P & <0.0001\end{aligned}$ & $\begin{aligned} 270 & \text { vs. } 136(87)(63) \\
P & <0.0001\end{aligned}$ & $\begin{array}{l}\text { 691 vs. } 150(56)(49) \\
P<0.0001\end{array}$ \\
\hline Kyeema vs. IR64 & WLR & $\begin{array}{l}196 \text { vs. } 182(48)(84) \\
0.24<P<0.48\end{array}$ & $\begin{aligned} 282 & \text { vs. } 195(70)(55) \\
P & <0.0017\end{aligned}$ & $\begin{aligned} 249 & \text { vs. } 136(72)(63) \\
P & <0.0003\end{aligned}$ & $\begin{array}{l}320 \text { vs. } 150(49)(49) \\
\quad P<0.001\end{array}$ \\
\hline Kyeema vs. Namaga & WLR & $\begin{array}{c}196 \text { vs. } 353(48)(58) \\
0.015<P<0.03\end{array}$ & $\begin{array}{c}282 \text { vs. } 480(70)(37) \\
0.023<P<0.046\end{array}$ & $\begin{array}{c}249 \text { vs. } 270(72)(87) \\
0.15<P<0.29\end{array}$ & $\begin{array}{c}320 \text { vs. } 691(49)(56) \\
0.006<P<0.013\end{array}$ \\
\hline
\end{tabular}

${ }^{a}$ The median rust infection site area in square micrometers measured on each rice cultivar being compared. The number of infection sites measured for each cultivar in each experiment is shown in parentheses with Mann Whitney U test probability values comparing the spectrum of infection site areas measured on each cultivar shown beneath. Statistically significantly different distributions of infection sites areas $(P<0.01)$ are in bold. The area of a single rice mesophyll cells is approximately $80 \mu \mathrm{m}^{2}$. 
A similar, albeit more modest, reproducible difference in the growth of WLR was observed among these three rice cultivars at the $0.01 \%$ significance level (Fig. 5B; Table 3). IR64 was again consistently the most restrictive in terms of rust growth compared with the other two cultivars, apart from a single comparison with Kyeema (Fig. 5; Table 3, experiment 1). No consistent difference in WLR growth was observed between Namaga and Kyeema based on Mann Whitney U test results, with only one experiment in four showing a significant difference (Table 3). Overall, the median infection site areas of WLR were much less in these experiments compared with the preceding WSR experiments (Table 3).

Rice has previously been reported to show substantial variation in free SA content between different rice cultivars, with SA levels ranging from 0.01 to $37.19 \mu \mathrm{g} / \mathrm{g} \mathrm{FW}$ (Raskin et al. 1990; Silverman et al. 1995). Free SA levels were measured in rice seedlings of IR64, Kyeema, and Namaga, when grown side-byside, using high-performance liquid chromatography (HPLC) analysis. IR64 was shown to have 3.5 times higher levels of SA compared with either Kyeema or Namaga $(P=0.04$ and 0.02 , respectively) (Fig. 5D), thereby raising a possible association between reduced SA levels and increased WSR and WLR growth on these latter two cultivars. No increase in free SA accumulation was observed in these three rice cultivar following inoculation with WSR (data not shown). Unlike most plants, rice is atypical in that it contains high levels of SA compared with other plant species and previous reports have shown no increase in rice SA levels upon infection with either avirulent or virulent adapted pathogens (Silverman et al. 1995).

In contrast to the variation observed for WSR and WLR, when these three rice cultivars were infected with either BLR or common maize rust no consistent difference in rust growth was apparent. From three replicate experiments with barley leaf rust, the majority (i.e., 7/9) of comparisons between these three cultivars were not statistically significantly different. Similarly, from four replicated experiments using maize rust, 9 of 12 comparisons between cultivars were not significantly different (data not shown).

\section{Heritability of NHR efficacy in rice.}

To examine the heritability of the differential NHR response of Kyeema and IR64 rice to WSR, a cross was made between these two cultivars. An F2 family of 31 individuals was infected with WSR when seedlings were at the three-leaf stage and infected tissue was harvested 14 days postinfection. When these same seedlings had progressed to the sixth-leaf stage, they were reinoculated with WSR and tissue was harvested from the fifth and sixth leaves 14 days postinoculation. An average of 30 rust infection sites was measured for each plant at each time point and median infection site area calculated.

Fig. 5. A, Median infection site areas in square micrometers ( $y$ axis) determined for growth of wheat stem rust 21-0 on 'IR64' (white columns), 'Namaga' (black columns), and 'Kyeema' (gray columns) rice over four experiments. B, Median infection site areas in square micrometers determined for IR64 (white columns), Namaga (black columns), and Kyeema (gray columns) rice after infection with wheat leaf rust. Four experiments are shown using tissue that was harvested after $11,8,13$, and 13 days postinoculation, respectively. $\mathbf{C}$, Graphs showing median infection site area measurements of wheat stem rust isolates 21-0 (black columns) and 326 (gray columns) when grown on IR64 (graphs on left) and Namaga (graphs on right) rice. The $y$ axis indicates median infection site areas in square micrometers. Individual leaves from the same seedlings were inoculated with either rust at the same time and tissue harvested and measured at the same time. D, Salicylic acid (SA) content of uninfected leaf tissue from IR64, Kyeema, and Namaga rice. The $y$ axis indicates SA concentrations in micrograms of SA per gram fresh weight of leaf tissue.

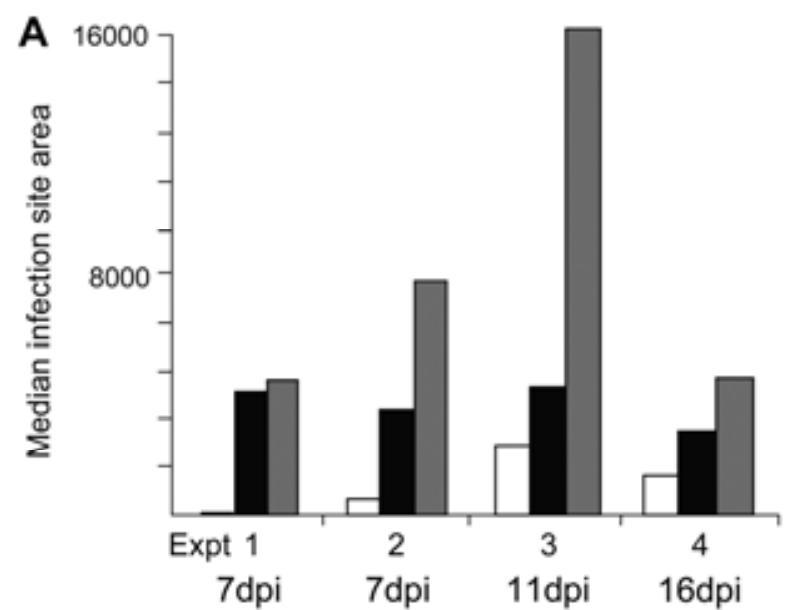

B

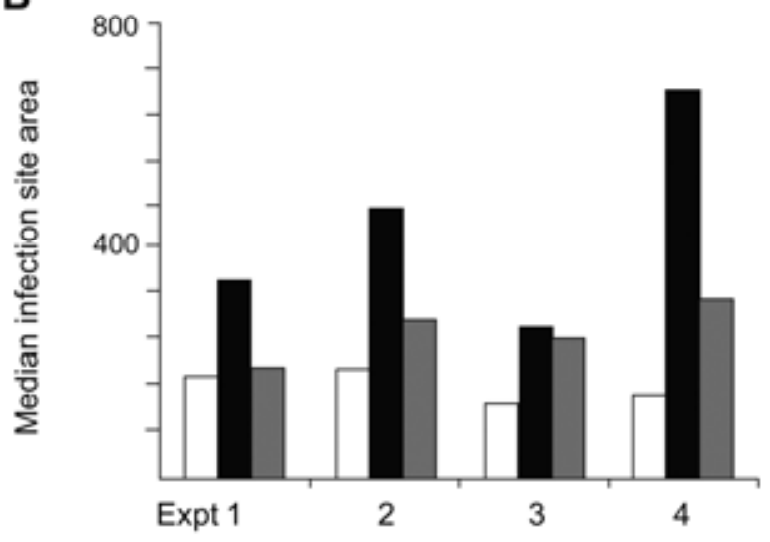

C

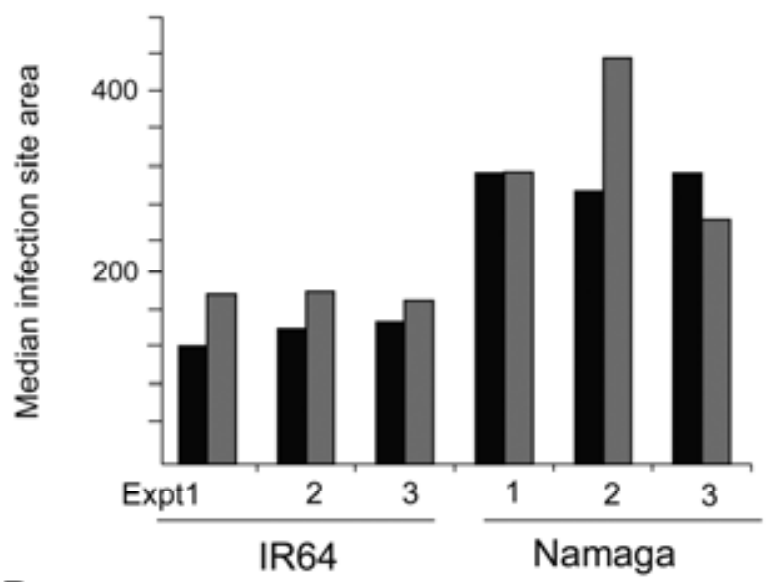

D

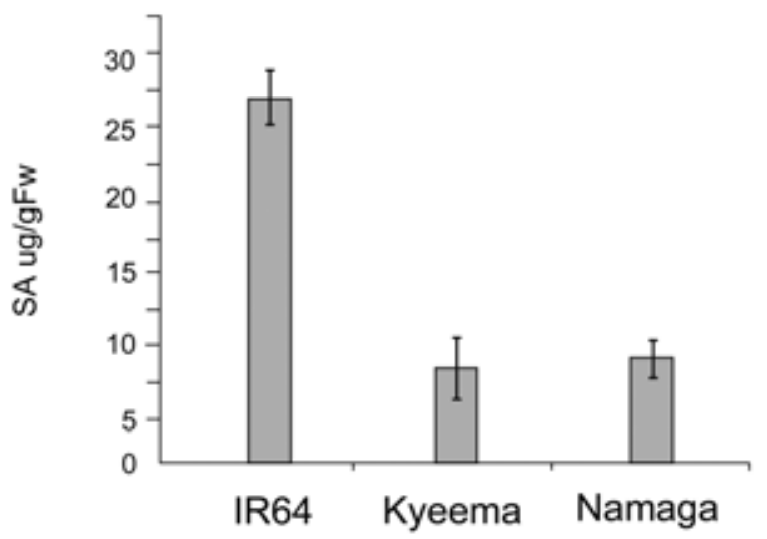


For each time point, all 31 plants were ranked based on smallest to largest median infection site area.

Spearman rank correlation coefficient analysis indicated that a highly statistically significant correlation was apparent between median infection site area rankings, with $P=0.008$. However, the correlation coefficient was relatively modest (0.48). From this analysis, we conclude that there is heritable difference existing among these F2 progeny for the efficacy of the NHR response to WSR. However, the variance in phenotype that arises from as-yet-unidentified environmental factors results in only a modest correlation between these two datasets. Therefore, resolution of this heritable difference in NHR into distinct QTL may not be possible among this F2 family.

\section{Assessment of genetic variation among WSR pathogens.}

To determine whether rice shows different infection responses to genetically distinct isolates of WSR, IR64 and Namaga were inoculated with two WSR isolates that possess different virulence patterns on wheat. These WSR isolates, 21-0 and 326, differ by six avirulence or virulence specificities (discussed below). To reduce experimental variation, each rust isolate was inoculated onto different leaves of the same rice seedlings, and individual leaves were harvested from these seedlings 10 days postinoculation. From a total of 531 infection site areas measured over three separate experiments, no consistent difference in median infection site areas was observed between these rust isolates when grown on the same rice cultivar (Fig. 5C; Table 4). For both WSR isolates, significantly more fungal growth occurred on Namaga compared with IR64 (Fig. 5C; Table 4), consistent with previous results (Fig. 4; Table 3). However, the median infection site areas of 21-0 rust in these experiments (Table 4) were significantly smaller than those observed in the preceding experiments (Table 3 ), again demonstrating substantial environmental influence on rust growth. Although it should be noted that large rust infection sites were also observed in these latter experiments, the frequency of small infection sites was obviously greater.

\section{Disruption in defense response genes or disruption in basal defense to Magnaporthe grisea an adapted rice pathogen does not alter the efficacy of NHR to WSR.}

Rice T-DNA insertion lines were obtained that contained insertions within rice homologues of known defense-related genes. Plants homozygous for the insertion were identified by polymerase chain reaction (PCR) analysis (Supplementary data). RNA blot analysis was then used to confirm both the inability of these plants to produce endogenous transcripts and their homozygosity. Rust infection data was collected only from seedlings that had been confirmed by RNA blot assay to not produce transcripts. At least three seedlings were measured in each experiment.
No difference in infection site areas of WSR 21-0 infections was observed between wild-type rice lines and rice lines that were deficient for either the OsRARl gene (Os02g0535400), which encodes a protein chaperone required for $N B S$ - LRR gene function and basal resistance (Shirasu et al. 1999; Wang et al. 2008) (Fig. 5D); the OsEDS1 gene (Os09g0392100), which encodes a lipase protein required for $T I R$ (toll interleukin 1 receptor)-NBS-LRR gene function and basal defense in Arabidopsis (Wiemar et al. 2005) (Fig. 5D); and the rice OsCeBip (Os03g0133400) gene, which encodes a plasma membrane receptor involved in recognition of chitin (Kaku et al. 2006; Miya et al. 2007) (data not shown).

We hypothesized that common host defense mechanisms may exist between NHR and basal resistance to the blast fungus, Magnaporthe oryzae, an adapted rice pathogen with long co-evolutionary history with rice. This hypothesis would predict that loss of resistance to blast would compromise NHR. Over 14,000 IR64 mutant lines (Wu et al. 2005) were screened with a virulent blast isolate to identify mutants with enhanced susceptibility to this strain. From this screen, 300 putative mutants were identified that showed increased blast susceptibility under natural infection. The reduced basal resistance of these plants was confirmed by reinoculation.

These 300 rice mutant lines with apparently reduced basal resistance were screened with WSR 21-0 for increased infection and growth by this nonadapted pathogen. However, microscopic assays on these plants revealed no increase in WSR growth compared with wild-type IR64 plants. These data suggest that either little overlap exists between the rice NHR response to WSR and the basal defense response to rice blast disease or, alternatively, an additional defense mechanism is apparent in these rice lines that can be circumvented by the adapted pathogen but not by cereal rusts. In this latter scenario, the effect on rust growth of disruption in basal defense would be masked by redundancy in resistance mechanisms.

\section{Challenge of rice plants with an autoecious rust pathogen of a dicotyledenous plant species.}

Melampsora lini is a rust pathogen of the dicotledenous plant species flax (L. ussitatisimum) and, unlike the above cereal rust species, it confines its lifecycle to a single plant species. Rusts of the genus Melampsora and Puccinia are classified taxonomically as being in different families of the same order, Uredinales. Intuitively, a rust species exclusively adapted for a dicotyledenous host species would be predicted to be less effective at infecting a monocotyledonous nonhost species compared with nonadapted cereal rust pathogens. To test this hypothesis, rice plants were challenged with flax rust urediospores.

When flax rust urediospores were inoculated onto 'Hoshangabad' flax, 92\% of germinated spores successfully produced

Table 4. Growth of wheat stem rust (WSR) isolates 21-0 and 326 on 'IR64' and 'Namaga' rice

\begin{tabular}{|c|c|c|c|c|c|c|}
\hline Cultivar & Exp. $^{a}$ & $\begin{array}{l}\text { WSR 21-0 } \\
\text { median ISA }^{\text {b }}\end{array}$ & $\begin{array}{c}\text { WSR } 326 \\
\text { median ISA }^{\text {b }}\end{array}$ & $\begin{array}{l}\mathrm{U} \text { test of } 21-0 \mathrm{vs.} 326 \\
\text { rust growth }^{\mathrm{c}}\end{array}$ & $\begin{array}{l}\text { U test of 21-0 WSR growth on } \\
\text { Namaga vs. IR64 }\end{array}$ & $\begin{array}{l}\mathrm{U} \text { test of } 326 \text { WSR growth on } \\
\text { Namaga vs. IR64 }\end{array}$ \\
\hline IR64 & 1 & $123(33)$ & $175(14)$ & $0.25<P<0.51$ & $P<0.0001$ & $0.0018<P<0.0035$ \\
\hline Namaga & 1 & $255(52)$ & $300(43)$ & $0.18<P<0.37$ & & $\ldots$ \\
\hline IR64 & 2 & $139(57)$ & $179(51)$ & $0.0004<P<0.0008$ & $P<0.0001$ & $P<0.0001$ \\
\hline Namaga & 2 & $269(46)$ & $420(64)$ & $0.02<P<0.05$ & & \\
\hline IR64 & 3 & $147(43)$ & $157(55)$ & $0.35<P<0.72$ & $P<0.0001$ & $0.0004<P<\mathbf{0 . 0 0 0 8}$ \\
\hline Namaga & 3 & $265(33)$ & $253(40)$ & $0.2<P<0.4$ & $\ldots$ & $\ldots$ \\
\hline
\end{tabular}

${ }^{a}$ In each experiment (Exp.), different leaves of the same IR64 and Namaga seedlings were inoculated with either WSR 21-0 or WSR 326 at the same time and incubated for the same period. Infection site areas in square micrometers were then determined for each rust isolate by pooling leaves from seedlings of the same cultivar infected with the same isolate. The area of a single rice mesophyll cells is approximately $80 \mu \mathrm{m}^{2}$.

${ }^{\mathrm{b}}$ ISA $=$ infection site areas. Numbers in parentheses indicate the number of infection sites measured.

${ }^{\mathrm{c}}$ Mann Whitney U tests were used to compare the distribution of ISAs observed for WSR 21-0 and WSR 326 growth on each rice cultivar. Significantly different infection site areas $(P<0.01)$ are in bold. 
appressoria (number of sites examined $[n]=93$ ) (Fig. $3 \mathrm{M}$ and N). In contrast, when four rice cultivars ('Doongara', 'Millin', 'Langi', and wild rice) were inoculated with flax rust urediospores, $37 \%$ of germinated spores successfully produced an appressorium over a rice stomate on these four cultivars $(n=$ 234) (Fig. 3O). Many flax rust appressoria that developed on rice leaves were morphologically aberrant when compared with appressoria that developed on flax plants, with the former infection structures often $(67 \%)$ producing hyphal-like extensions (Fig. 3M to O). In addition, $20 \%$ of germinated flax rust spores produced appressorial-like structures on rice that were not localized over a stomate (Fig. 3P and Q). Often (86\%) associated with these appressorial-like structures was a large amount of additional hyphal-like growth (Fig. 3R to U).

The aberrant structures observed when flax rust was grown on rice were not observed when this pathogen was grown on its natural host, flax. Similarly, when flax rust was inoculated onto a nonhost dicot species, Arabidopsis ecotype Landsberg, these aberrant infection structures were again absent. In this latter case, $41 \%$ of germinated flax rust spores successfully produced an appressorium over an Arabidopsis stomate $(n=$ 66 ) and $91 \%$ of these appressoria developed substomatal vesicles with occasional very short infection hyphae $(n=104)$ (data not shown).

Additional microscopic analysis of flax rust development on flax indicated that $99 \%$ of flax rust appressoria successfully entered the host leaf to produce infection hyphae, with haustoria usually also visible $(n=108)$ (Fig. 3M). In contrast, only $20 \%$ of flax rust appressoria that developed on rice went on to successfully enter the rice leaf and produce infection hyphae $(n=83)$ (Fig. 3V and W). In all cases, these infection hyphae were very short and were only produced by appressoria that did not have additional hyphal-like extensions.

In summary, $91 \%(92 \times 99 \%)$ of flax rust urediospores that germinate on flax plants successfully infect the host and produce infection hyphae within the leaf. In contrast, only $7.5 \%$ $(37 \times 20 \%)$ of flax spore germination events on rice produced short infection hyphae within the rice leaf. No evidence of haustorium production was observed for any flax rust infection site on either rice or Arabidopsis in this study.

\section{DISCUSSION}

All five species of cereal rust examined in this study have the capacity to infect rice and produce many of the infection structures required for the establishment of parasitism. All of these rust species are capable of producing large infection sites that encompass many (hundreds) rice mesophyll cells and produce haustoria. Given the finite resources contained within a single rust spore, the size of these larger, haustoria-producing infection sites argues that each nonadapted rust species has the ability to extract nutrients from the plant nonhost, prior to growth cessation by an NHR response.

In spite of the extensive growth occurring at some rust infection sites on rice, most attempted infections were generally more restricted, often confined to only substomatal vesicles that produced small infection hyphae with occasional haustoria. Therefore, a stochastic process of rust infection was observed on rice with a large variation in infection site size occurring between experiments and even upon a single leaf. This is somewhat analogous to the host mesothetic rust resistance response, whereby some cereal resistance genes engender a mixed response of sporulating pustules and hypersensitive lesions on the same leaf when challenged by the same pure race of the rust. Thus, for largely unknown reasons, large variations in rust development can occur in both NHR and host resistance responses on a single cereal leaf.
The NHR mechanisms that operate against cereal rusts on rice appear to occur at several levels. An obvious difference in infection efficiency was demonstrated for WSR and BLR on their respective host species compared with rice. An approximately twofold difference in successful stomate location and appressorium formation was observed for rust infection of host species compared with rice. This difference may be due to inappropriate biochemical or thigmotrophic signals arising from the nonhost. The altered appressorium morphology of WSR and BLR when grown on rice is consistent with this observation.

A probable absence of appropriate physical and chemical signals was dramatically illustrated when rice was infected with the rust of flax and aberrant infection structures were produced. These aberrant growths were not observed on Arabidopsis and are likely to be a consequence of the differences in leaf architecture of cereals and dicot plants (Wynn 1981). Similar limited fungal development was observed when Arabidopsis was inoculated with urediospores of WSR (Shafiei et al. 2007). It would be of interest to infect Arabidopsis with WSR basidispores, given that the sexual phase of WSR occurs exclusively on dicot plant species (genus Berberis).

Therefore, basic incompatibility appears to reduce the efficiency of cereal rust infection of rice but it is insufficient to prevent approximately half of attempted colonization events. Upon rust entry into the rice leaf, the nonhost responds with the production of reactive oxygen species (i.e., hydrogen peroxide), deposition of callose, and occasional cell death, as indicated by autofluorescence. Both hydrogen peroxide production and autofluorescence can be observed at the same infection site. For technical reasons, we have not examined callose deposition at the same time. The majority of rust infections did not evoke rice cell death that led to autofluorescence, suggesting that this response is not essential for cessation of nonadapted pathogen growth. These responses were observed on all three rice cultivars (IR64, Kyeema, and Namaga) examined in this study and were also apparent at both small and large infection sites. The difference in rust infection site sizes observed on a single rice leaf could be a consequence of delayed activation of NHR or, alternatively, a transiently successful suppression of the NHR response by the nonadapted pathogen.

The immunity of rice to rust could theoretically have been acquired by two routes. Either rice evolved from a rust-susceptible progenitor grass and acquired resistance or, alternatively, the NHR mechanisms of rice evolved in the absence of cereal rust pathogens and are in no way specifically adapted for defense against these species. The prevailing model of $P$. graminis evolution, for example, proposed by Leppik (1961) favors the latter hypothesis. The progenitor of $P$. graminis was believed to have existed as the aecial form of the species which parasitized dicot plants of the ancestral Berberidaceae in the Northern Hemisphere, prior to the evolution of the Mahonia and Berberis genera in this family. The grasses (Poaceae family) evolved and formed subfamilies during their subsequent radiation. Some species (particularly members of the subfamily Pooideae) came into close association with infected Berberis plants, leading to the parasitism of these grasses and subsequent evolution of the modern macrocyclic, heteroecious species of P. graminis (Leppik 1961; Wahl et al. 1984).

For this reason, the large number of grasses species (possibly in excess of 350) infected by $P$. graminis are mainly all members of the Pooideae family while grasses from some other Gramineae subfamilies, such as Erhartoideae, of which rice is a member, are not parasitized by this species (Leppik 1961; Wahl et al. 1984). If this evolutionary model is correct, the active NHR response of rice to $P$. graminis has evolved in the absence of this nonadapted pathogen. Therefore, the in- 
duced NHR responses of rice to $P$. graminis infection of rice may be due to PAMP recognition rather than the recognition of specific $P$. graminis effector molecules.

In contrast to the above model, a number of reports have claimed that a few members of the Erhartoideae subfamily are hosts for Puccinia rusts (Afshan et al. 2010; Cummins 1971). Reports from the early 20th century have also recorded rice as being a host for P. graminis f. sp oryzae (Cummins 1971; Ou 1985 ) and $U$. coronatus (Ou 1985). However, the absence of subsequent identification of rust diseases on rice in the intervening 70 years makes their proposed parasitism highly questionable, particularly given the massive areas of cereal cultivation and increased diversification of cereals grown in the same region.

In rice, both the OsCeBip chitin PAMP receptor and OsRARI chaperonin protein have demonstrated roles in basal defense (Takahashi et al. 2007; Thao et al. 2007; Wang et al. 2008). The OsRAR1 protein has not been shown to function in NBSLRR-mediated resistance in rice but homologous in wheat and barley are required for function of some $\mathrm{R}$ proteins (Scofield et al. 2005; Shirasu and Schulze-Lefert 2003). The role of OsEDS1 is unknown in rice but the equivalent Arabidopsis protein plays a central role in a regulatory pathway that is required for basal resistance, SA-mediated signaling, TIR-NBSLRR R protein function, and NHR (Lipka et al. 2008, 2010; Weirmer et al. 2005). Disruption of these genes in rice did not increase the growth of WSR, arguing for a significant amount of redundancy in the rice NHR response to this nonadapted pathogen. In contrast, SA deficiency has previously been shown to reduce the NHR response of Arabidopsis to nonadapted powdery mildews in a pen3/nahG mutant background (Stein et al. 2006) and increase growth of a nonadapted bean rust pathogen (Mellersch and Heath 2003). Therefore, it is of interest that the levels of SA measured in three rice cultivars parallel the observed extent of growth of both WSR and WLR in these plants, although additional testing is required to confirm a corelation between SA level and rust growth.

Genetic variation was observed between different rice cultivars for the efficacy of NHR to both WSR and WLR. Natural variation in the NHR response of Arabidopsis to WLR has been previously reported and co-related with increased levels of camalexin, SA, and defense gene expression upon fungal inoculation (Shafiei et al. 2007). Similar variation was observed in Arabidopsis upon infection with bean leaf rust, where haustoria formation occurred in only a single accession out of 17 assayed (Mellersch and Heath 2003). In both these examples, the extent of fungal colonization was far more restricted (i.e., less than 10 mesophyll cells) than what is observed at some rice infection sites. The occurrence of near-NHR, as reported for the interaction between barley and WLR (Jaffary et al. 2008), is presumably an extrapolation of variability within the NHR response within a species.

Table 5. Rust strains used in this study

\begin{tabular}{lll}
\hline Rust species & \multicolumn{1}{c}{ Common name } & \multicolumn{1}{c}{ Isolate $^{\mathbf{a}}$} \\
\hline $\begin{array}{l}\text { Puccinia graminis } \\
\text { f. sp. tritici }\end{array}$ & Wheat stem rust & $21-0$ (PBIC 540129) \\
$\begin{array}{l}\text { P. graminis f. sp. } \\
\text { tritici }\end{array}$ & Wheat stem rust & 326 \\
P. hordei & Barley leaf rust & 4653P+ (PBIC 990492) \\
P. striiformis & Wheat stripe rust & 104E137A- \\
P. triticinia & Wheat leaf rust & 104-1236(7)11 (PBIC \\
& & $89172)$ \\
P. sorghi & Common maize rust & R1 \\
Melampsora lini & Flax rust & 228 \\
\hline
\end{tabular}

${ }^{a}$ PBIC numbers indicate catalogue numbers at the cereal rust collection of the University of Sydney, Plant Breeding Institute, Cobbitty, Australia.
Natural variation in basal resistance (defined as polygenic, non-race specific, nonhypersensitive, partial resistance) to fungal and bacterial pathogens has been well established (Aghnoum et al. 2010; Denby et al. 2004; Kover and Schaal 2002; Marcel et al. 2007; Perchepied et al. 2006) and variation in effectortriggered immunity mediated by $\mathrm{R}$ proteins has been known for many years to range from partial resistance to complete immunity. Therefore, it is unsurprising that NHR effectiveness also shows natural variation, further reinforcing the established continuum of possible plant-microbe outcomes that are dependent upon the genotypes of both interacting organisms.

\section{MATERIALS AND METHODS}

\section{Propagation of rust species.}

Cereal rusts (Table 5) were propagated on host species by inoculation of seedlings at the three-leaf stage with an aqueous suspension of rust urediospores. Inoculated seedlings were incubated overnight at $16^{\circ} \mathrm{C}$ in a humid chamber and subsequently transferred to the glasshouse for the development of rust pustules. Wheat rusts ( $P$. graminis, $P$. striiformis, and $P$. triticinia) were propagated on 'Sonora' wheat, barley leaf rust (P. hordei) was grown on Golden Promise barley, while maize rust ( $P$. sorghi) was grown on 'HiII' maize. Flax rust (M. lini) was grown as previously described by Lawrence (1988) on Hoshangabad flax. Rust urediospores were collected from host species and used immediately for inoculation of rice seedlings in nonhost assays. Two WSR isolates, 326 and 21-0, were used in this study and have the following pathotype designations. Race 21-0 is recognized by resistance genes $\operatorname{Sr} 5, \operatorname{Sr} 8 a, \operatorname{Sr} 8 b$, Sr9b, Sr9e, Sr11, Sr15, Sr17, Sr21, Sr24, Sr26, Sr27, Sr30, $\mathrm{Sr} 31, \mathrm{Sr} 32, \mathrm{Sr} 35, \mathrm{Sr} 36$, and $\mathrm{Sr} 38$ but is virulent on plants containing $\operatorname{Sr} 6, S r 7 b$, and $S r 9 g$. Race 326 is recognized by resistance genes $\mathrm{Sr} 5, \mathrm{Sr} 7 b, \mathrm{Sr} 8 b, \mathrm{Sr} 9 e, \mathrm{Sr} 9 g, \mathrm{Sr} 15, \mathrm{Sr} 21, \mathrm{Sr} 24$, $\mathrm{Sr} 26, \mathrm{Sr} 27, \mathrm{Sr} 30, \mathrm{Sr} 31, \mathrm{Sr} 32, \mathrm{Sr} 35, \mathrm{Sr} 36$, and $\mathrm{Sr} 38$ but is virulent on plants containing $\mathrm{Sr} 6, \mathrm{Sr} 8 \mathrm{~A}, \mathrm{Sr} 9 b, \mathrm{Sr} 11$, and $\mathrm{Sr} 17$.

\section{Rice lines and rust infection.}

Rice lines IR64, Kyeema, Namaga, Millin, Doongara, Opus, Amaroo, Langi, Koshihikara, Pelde, purple rice, and wild rice were supplied by N. Upadhyaya (CSIRO, Canberra, Australia). Rice T-DNA insertion mutants were identified using the Salk Institute Rice Functional Genomic Express Database and seed of T-DNA insertion lines obtained from G. An, Pohang Biotech Centre (Pohang, Korea) (Jeon et al. 2000; Jeong et al. 2006). Rice plants were grown under a growth regime of $21^{\circ} \mathrm{C}$ for $16 \mathrm{~h}$ of light and $16^{\circ} \mathrm{C}$ for $8 \mathrm{~h}$ of darkness. Seedlings were inoculated with fresh rust spores at the three- to four-leaf stage and incubated for $24 \mathrm{~h}$ in a humid chamber at $16^{\circ} \mathrm{C}$ before transfer to the glasshouse.

Screening rice mutants for enhanced susceptibility to blast.

To obtain rice mutants with enhanced susceptibility to rice blast disease, IR64 mutant collections were produced by chemical and irradiation mutagenesis (Wu et al. 2005). Individual mutant lines ( 75 to 100 seeds) in the M4 generation were sown in rows (15 to $20 \mathrm{~cm}$ long and $10 \mathrm{~cm}$ apart) in the blast screening nursery at IRRI Experimental Farm, Los Banos, Laguna, Philippines. Each nursery bed $(15.7$ by $1.17 \mathrm{~m})$ was divided lengthwise into two subplots to accommodate 400 mutant lines, including susceptible ' $\mathrm{Co39}$ ' and wild-type IR64 as wild-type controls. Highly susceptible 'IR50', 'IR72', and 'Co39' were interplanted in the nursery bed as spreaders to ensure a diverse pathogen population. Ten days after sowing, the plots were covered by polyvinyl plastic in the afternoon and removed in the morning every day for 10 days to achieve multiple cycles of infection. The seedlings were exposed to 
natural inoculum for over 20 days. The mutant lines were assessed for diseased leaf area (DLA) at 21 days after sowing as previously described (Liu et al. 2011). Under this environment, the wild-type IR64 exhibited 20 to $40 \%$ DLA. Mutant lines that showed enhanced susceptibility relative to IR64 (with $>50 \%$ DLA) were selected. In total, approximately 14,000 mutant lines were screened. Selected mutant lines were subjected to a second field evaluation to confirm the phenotype. Seed of selected lines from the same M4 generation were sent to CSIRO for rust infection assay.

\section{Identification of homozygous rice T-DNA insertion lines.}

DNA extractions were undertaken as described by Ayliffe and associates (2000). PCR analysis was used to identify plants homozygous for T-DNA insertions. A primer (Table 6) specific for the T-DNA vector and a primer specific for the flanking endogenous gene sequence were used to identify those plants that contained at least one T-DNA insertion allele. These DNAs were reamplified using gene-specific primers that spanned the T-DNA insertion site. Those plants that were PCR positive for the DNA insertion allele and PCR negative for the endogenous gene sequence were considered to be homozygous for the insertion allele. The inability of these lines to produce endogenous transcripts was subsequently confirmed by RNA blot analysis.

\section{Histological examination of fungal infection structures.}

For microscopic visualization of spore germination and appressoria formation, fresh infected leaf tissue was stained by immersion in a $50 \mathrm{mM}$ Tris $(\mathrm{pH}$ 7.5) solution containing 0.05\% Silwet L-77 (Lehle Seeds, Round Rock, TX, U.S.A.) and WGA at $20 \mu \mathrm{g} / \mathrm{ml}$ conjugated to the flurophore alexa 488 (Invitrogen, San Diego, CA, U.S.A.). After 5 min of staining, the tissue was rinsed in $50 \mathrm{mM}$ Tris $(\mathrm{pH} 7.5)$ and mounted on a glass slide for microscopy. WGA binds specifically to $\mathrm{N}$-acetyl-glucosamine (i.e., chitin) and has been used extensively in staining of fungal material (Allen et al. 1973; Bhavanandan and Kaltic 1979; Meyberg 1988). The above method allows good resolution of external infection structures but does not allow internal structures to be observed. However, additional tissue-clearing steps can result in removal of infection structures from the leaf surface, particularly spore germ tubes that have not produced an appressorium.

For visualization of internal infection structures, we have developed the following simple staining procedure. To clear leaf samples, tissue was cut into $2-\mathrm{cm}$ pieces and autoclaved in a 10 $\mathrm{ml}$ screw cap tube containing $5 \mathrm{ml}$ of $1 \mathrm{M} \mathrm{KOH}$ and $0.05 \%$ Silwet L-77 (Hood and Shew 1996). Following autoclaving, the $\mathrm{KOH}$ solution was gently poured off and replaced with $10 \mathrm{ml}$ of $50 \mathrm{mM}$ Tris $(\mathrm{pH} \mathrm{7.5)}$. The tissue is quite fragile after autoclaving. This solution was then replaced with another $10 \mathrm{ml}$ of Tris ( $\mathrm{pH}$ 7.5) and the tissue left for $20 \mathrm{~min}$. It is important for the tissue $\mathrm{pH}$ to be neutralized prior to staining. After $20 \mathrm{~min}$, a majority of the Tris solution was removed to leave the tissue in a minimum volume. A $1-\mathrm{mg} / \mathrm{ml}$ solution of WGA-alexa was then added to the tissue to produce a final stain concentration of 20 $\mu \mathrm{g} / \mathrm{ml}$. Tissue was stained for $15 \mathrm{~min}$ prior to microscopy. Additional staining times (e.g., overnight) did not result in increased background. After staining, the tissue was removed from the tube by rinsing it out with $50 \mathrm{mM}$ Tris $(\mathrm{pH} 7.5)$ into a glass petri dish and then gently placing it on a microscope slide using forceps. After placing the tissue on the slide, gently spraying it with $50 \mathrm{mM}$ Tris solution from a squeeze bottle caused the tissue to unravel prior to adding a coverslip. All WGA-alexa-stained tissue was examined under blue light excitation.

Callose deposition in rust-infected rice plants was visualized under UV light after staining with a $0.005 \%$ aniline blue solu- tion (Hood and Shew 1996), while hydrogen peroxide production was detected in plant tissue by staining with DAB stain (Sigma-Aldrich, St. Louis) (Thordal-Christensen et al. 1997).

\section{Measurements of rust infection site areas.}

Cereal rust infection site areas were calculated by microscopy of rust infection structures present within the leaf as described above using WGA-alexa staining. Infection sites were photographed under $\times 20$ magnification using a focal plane that maximized the area of each infection site. Only those infection sites that had produced infection hyphae within the plant were measured. Infections that produced only substomatal vesicles, appressoria, or germ tubes were not included. The length (L) and width (W) of each infection site was measured using the polyline facility of the AnalySIS Life Science Professional program (Olympus, Mt. Waverley, Australia). Each infection site was assumed to be approximately oval or circular in shape and the infection site area was calculated by $\mathrm{L} / 2 \times \mathrm{W} / 2 \times 3.14$. Because rust infection site areas did not show a normal distribution, nonparametric statistical analyses were required; hence, the Mann Whitney U test was used. The validity of this statistical analysis for these datasets was supported by Kruskal-Wallis one-way analysis of variance (data not shown). The Mann Whitney U test is based upon median values; hence, median values are used for graphical presentation of data. Median values do not have a standard error associated with them.

\section{SA analysis.}

SA content was determined essentially as described by Raskin and associates (1989, 1990). Leaf samples (150 mg) were spiked with internal standard (o-anisic acid, $5 \mu \mathrm{g}$ ) and sequentially extracted with methanol (90 and $100 \%$, vol/vol). Supernatants were dried, resuspended in 5\% trichloroacetic acid, and extracted with cyclopentane/ethyl acetate/isopropanol (49.5:49.5:1, vol/vol). Samples were vortexed, sonicated, and centrifuged at each step. The upper, organic layer was dried in an $\mathrm{N}_{2}$ stream, resuspended in HPLC mobile phase, and filtered through $0.45-\mu \mathrm{m}$ polytetrafluoroethylene filters prior to HPLC analysis. Each extraction procedure was performed in triplicate and included procedural blanks and control samples. Analyses were performed using an Agilent 1200 Series reverse phase HPLC system consisting of a quaternary pump equipped with a thermostat auto-sampler (injection volume: $20 \mu \mathrm{l}$ ) and a fluorescence detector $(8-\mu$ l flow cell; photomultiplier gain set at

Table 6. Primers and probes used in this study

\begin{tabular}{ll}
\hline Primer, probe & \multicolumn{1}{c}{ Sequence, description } \\
\hline Primer & \\
CeBipA & TTAGCGTTTTATCGTTCCGG \\
CeBipB & GCATCACGTTAGAGCCTTCC \\
RAR1A & GCATGCACCCACAACATAAG \\
RAR1B & ATTTTGTTGCGTAGGGATGG \\
EDS1A & ACACTGGCTCCTACCTCT \\
EDS1B & CAAAGTTCATGCATATGG \\
RB & GGGGTTTCTACAGGACGTAAC \\
Probe & \\
CeBip probe & A 100-bp XhoI/EcoRI fragment from rice cDNA clone \\
& J023146H06 (accession number AK073032) corre- \\
& sponding to 5' untranslated leader sequence of the \\
RAR1 probe & A 1.25-kb fragment encoding exons 1 to 3 of OsRAR1 \\
& and corresponding to nucleotides 55,003 to 56,262 of \\
& BAC clone OJ112_G07 (accession number \\
EDS1 probe & AP004156) \\
& to 2,083 of cDNA clone J023007E18 (accession num- \\
& ber AK100117) \\
\hline
\end{tabular}


10). Online fluorescence detection was performed using a programmed excitation and emission wavelength of 297 and 407 $\mathrm{nm}$ for SA and 235 and 362nm for o-anisic acid. Fluorescence spectra were collected to check similarities with spectrum from authentic standards (Sigma-Aldrich). Analyses were run under a solvent gradient of $20 \mu \mathrm{M} \mathrm{KH}_{2} \mathrm{PO}_{4}$ buffered at $\mathrm{pH} 2.5$ (solvent A) and $100 \%$ methanol (solvent B) at a flow rate of $1.1 \mathrm{ml} / \mathrm{min}$. A guard column (Security Guard C18 $4 \times 3.0 \mathrm{~mm}$ ) was used in combination with the analytical column (Alltima C18 column; $150 \mathrm{~mm}$ by $4.6 \mathrm{~mm}$ by $5 \mu \mathrm{m}$ ), which was set at $40^{\circ} \mathrm{C}$.

\section{ACKNOWLEDGMENTS}

We thank the Bill and Melinda Gates Foundation for funding of this project as part of the Borlaug Global Rust Initiative, Durable Rust Resistance in Wheat project; L. Lake, S. Chakraborti, C. Jackson, and R. Poels for technical assistance; S. Madamba for screening for blast susceptible mutants; the University of Sydney, Plant Breeding Institute, Australia, for kindly providing wheat rust cultures.

\section{LITERATURE CITED}

Afshan, N.-S., Khalid, A. N., and Niazi, A. R. 2010. Three new species of rust fungi from Pakistan. Mycol. Prog. 9:485-490.

Aghnoum, R., Marcel, T. C., Johrde, A., Pecchioni, N., Schweizer, P., and Niks, R. E. 2010. Basal host resistance of barley to powdery mildew: connecting quantitative trait loci and candidate genes. Mol. PlantMicrobe Interact. 23:91-102.

Allen, A. K., Neuberger, A., and Sharon, N. 1973. The purification, composition and specificity of wheat germ agglutinin. Biochem. J. 131:155162.

Atienza, S. G., Jafary, H., and Niks, R. E. 2004. Accumulation of genes for susceptibility to rust fungi for which barley is nearly a nonhost results in two barley lines with extreme multiple susceptibility. Planta 220:7179.

Ayliffe, M. A., Collins, N. C., Ellis, J. G., and Pryor, A. J. 2000. The maize $r p 1$ rust resistance gene identifies homologues in barley that have been subjected to diversifying selection. Theor. Appl. Genet. 100:985-1154

Ayliffe, M., Singh, R., and Lagudah, E. 2008. Durable resistance to stem rust needed. Curr. Opin. Plant Biol. 11:187-192.

Bhavanandan V. P., and Katlic, A. W. 1979. The interaction of wheat germ agglutinin with sialoglycoproteins. J. Biol. Chem. 254:4000-4008.

Borlaug, N. E. 2000. Ending world hunger. The promise of biotechnology and the threat of anti-science zealotry. Plant Physiol. 124:487-490.

Collins, N. C., Thordal-Christensen, H., Lipka, V., Bau, S., Kombrink, E., Qui, J. L., Huckelhoven, R., Stein, M., Freialdenhoven, A., Somerville, S. C., and Schulze-Lefert, P. 2003. SNARE-protein-mediated disease resistance at the plant cell wall. Nature 425:973-977.

Cummins, G. B. 1971. The Rust Fungi of Cereals, Grasses and Bamboos. Springer Verlag, New York.

Denby, K. J., Kumar, P., and Kliebenstein, D. J. 2004. Identification of Botrytis cinerea susceptibility loci in Arabidopsis thaliana. Plant J. 38:473-486.

Heath, M. C. 2000. Nonhost resistance and nonspecific plant defenses. Curr. Opin. Plant Biol. 3:3154-319.

Hogenhout, S. A., van der Hoorn, R. A. L., Terauchi, R., and Kamoun, S. 2009. Emerging concepts in effector biology of plant-associated organisms. Mol. Plant-Microbe Interact. 22:115-122.

Hood, M. E., and Shew, H. D. 1996. Applications of KOH-aniline blue fluorescence in the study of plant fungal interactions. Phytopathology 86:704-708.

Jafary, H., Albertazzi, G., Marcel, T. C., and Niks, R. E. 2008. High diversity of genes for nonhost resistance of barley to heterologous rust fungi. Genetics 78:2327-2339.

Jeon, J. S., Lee, S., Jung, K.-H., Jun, S.-H., Jeong, D.-H., Lee, J., Kim, C., Jang, S., Lee, S.-Y., Yang, K., Nam, J.-M., An, K., Han, M.-J., Sung, R.J., Choi, H.-S., Yu, J.-W., Choi, J.-H., Cho, S-Y., Cha, S.-S., and An, G. 2000. T-DNA insertional mutagenesis for functional genomics in rice. Plant J. 22:561-570.

Jeong, D.-H., An, S., Park, S., Kang, H.-G., Park, G.-G., Kim, S.-R., Sim, J., Kim, Y.-O., Kim, M.-K., Kim, S.-R., Kim, J., Shin, M., Jung, M., and An, G. 2006. Generation of flanking sequence-tag database for activation-tagging lines in japonica rice. Plant J. 45:123-132.

Jones, J. D. G., and Dangl, J. L. 2006. The plant immune system. Nature
444:323-329.

Kaku, H., Nishizawa, Y., Ishii-Minami, N., Akimoto-Tomiyama, C., Dohmae, N., Takio, K., Minami, E., and Shibuya, N. 2006. Plant cells recognize chitin fragments for defense signaling though a plasma membrane receptor. Proc. Natl. Acad. Sci. U.S.A. 103:11086-11091.

Kover, P. X., and Schaal, B. A. 2002. Genetic variation for disease resistance and tolerance among Arabidopsis thaliana accessions. Proc. Natl. Acad. Sci. U.S.A. 99:11270-11274.

Lawrence, G. J. 1988. Melampsora lini, rust of flax and linseed. Adv. Plant Pathol. 6:313-331.

Leppik, E. E. 1961. IV. Stem rust genealogy. Mycologia 53:378-405.

Lipka, U., Fuchs, R., and Lipka, V. 2008. Arabidopsis non-host resistance to powdery mildew. Curr. Opin. Plant Biol. 11:404-411.

Lipka, U., Fuchs, R., Kuhns, C., Petutschnig, E., and Lipka, V. 2010. Live and let die-Arabidopsis nonhost resistance to powdery mildews. Eur. J. Cell Biol. 89:194-199.

Lipka, V., Dittgen, J., Bednarek, P., Bhat, R., Wiermer, M., Stein, M., Landtag, J., Brandt, W., Rosahl, S., Scheel, D., Lllorente, F., Molina, A., Parker, J., Somerville, S., and Schulze-Lefert, P. 2005. Pre- and postinvasion defenses both contribute to nonhost resistance in Arabidopsis. Science 310:1180-1183.

Liu, Y., Zhu, X. Y., Zhang, S., Bernardo, M., Edwards, J., Galbraith, D. W., Leach, J. E., Zhang, G., Liu, B., and Leung, H. 2011. Dissecting quantitative resistance against blast disease using heterogeneous inbred family lines in rice. Theor. Appl. Genet. 122:341-353.

Marcel, T. C., Varshney, R. K., Barbieri, M., Jafary, H., de Kock, M. J. D, Graner, A., and Niks, R. E. 2007. A high-density consensus map of barley to compare the distribution of QTLs for partial resistance to Puccinia hordei and of defence gene homologues. Theor. Appl. Genet. 114:487-500.

Mellersch, D. G., and Heath, M. C. 2003. An investigation into the involvement of defense signaling pathways in components of the nonhost resistance of Arabidopsis to rust fungi also reveals a model system for studying rust fungal compatibility. Mol. Plant-Microbe Interact. 16:398404.

Meyberg, M. 1988. Selective staining of fungal hyphae in parasitic and symbiotic plant-fungus associations. Histochemistry 88:197-199.

Miya, A., Albert, P., Shinya, T., Desaki, Y., Ichimura, K., Shirasu, K. Narusaka, Y., Kawakami, N., Kaku, H., and Shibuya, N. 2007. CERK1, a LysM receptor kinase, is essential for chitin elicitor signaling in Arabidopsis. Proc. Natl. Acad. Sci. U.S.A. 104:19613-19618.

Ou, S. H. 1985. Rice Diseases, 2nd ed. Commonwealth Mycological Institute, Commonwealth Agricultural Bureau, Kew, U.K.

Perchepied, L., Kroj, T., Tronchet, M., Loudet, O., and Roby D 2006. Natural variation in partial resistance to Pseudomonas syringae is controlled by two major QTLs in Arabidopsis thaliana. PLoS One 1:e123. Online publication. doi:10.1371/journal.pone.0000123

Raskin, I., Turner, I. M., and Melander, W. R. 1989. Regulation of heat production in the inflorescences of an Arum lily by endogenous salicylic acid. Proc. Natl. Acad. Sci. U.S.A. 86:2214-2218.

Raskin, I., Skubatz, H., Tang, W., and Meeuse, B. J. D. 1990. Salicylic acid levels in thermogenic and nonthermogenic plants. Ann. Bot. 66:363-373.

Roelfs, A. P., and Bushnell, W. R. 1985. The Cereal Rusts, vol. 2. Diseases, Distributions, Epidemiology and Control. Academic Press, Orlando, FL, U.S.A.

Scofield, S. R., Huang, L., Brandt, A. S., and Gill, B. S. 2005. Development of a virus-induced gene-silencing system for hexaploid wheat and its use in functional analysis of the Lr21-mediated leaf rust resistance pathway. Plant Physiol. 138:2165-2173.

Schulze-Lefert, P., and Pangstruga, R. 2011. A molecular evolutionary concept connecting nonhost resistance, pathogen host range and pathogen speciation. Trends Plant Sci. 16:117-125.

Shafiei, R., Hang, C., Kang, J.-G., and Loake, G. J. 2007. Identification of loci controlling non-host disease resistance in Arabidopsis against the leaf rust pathogen Puccinia triticina. Mol. Plant Pathol. 8:773784.

Shirasu, K., Lahaye , T., Tan, M. W., Zhou, F., Azevedo, C., and SchulzeLefert, P. 1999. A novel class of eukaryotic zinc-binding proteins is required for disease resistance signalling in barley and development in C. elegans. Cell 99:355-366.

Shirasu, K., and Schulze-Lefert, P. 2003. Complex formation, promiscuity and multifunctionality: protein interactions in disease-resistance pathways. Trends Plant Sci. 8:252-258.

Silverman, P., Seskar, M., Kanter, D., Scheizer, P., Metraux, J.-P., and Raskin, I. 1995. Salicylic acid in rice: biosynthesis, conjugation and possible role. Plant Physiol. 108:633-639.

Stein, M., Dittgen, J., Sanchez-Rodriguez, C., Hou, B.-H., Molina, A., Schulze-Lefert, P., Lipka, V., and Somerville, S. 2006. Arabidopsis PEN3/PDR8, an ATP binding cassette transporter, contributes to non- 
host resistance to inappropriate pathogens that enter by direct penetration. Plant Cell 18:731-746.

Stokstad, E. 2007. Deadly wheat fungus threatens world's breadbaskets. Science 315:1786.

Takahashi, A., Agrawal, G. K., Yamazaki, M., Onosato, K., Miyao, A., Kawasaki, T., Shimamoto, K., and Hirochika, H. 2007. Rice Ptila negatively regulates $R A R l$-dependent defense responses. Plant Cell 19:2940-2951

Thao, N. P., Chen, L., Nakashima, A., Hara, S.-I., Umemura, K., Takahashi, A., Shirasu, K., Kawasaki, T., and Shimamoto, K. 2007. RAR1 and HSP90 for, a complex with Rac/Rop GTPase and function in innateimmune responses in rice. Plant Cell 19:4035-4045.

Thordal-Christensen, H., Zhang, Z., Wei, Y., and Collinge, D. B. 1997. Subcellular localistaion of $\mathrm{H} 2 \mathrm{O} 2$ in plants. H202 accumulation in papillae and hypersensitive response during the barley powdery mildew interaction. Plant J. 11:1187-1194.

Wahl, I., Anikster, Y., Manisterski, J., and Segal, A. 1984. Evolution at the center of origin. Pages 39-77 in: Origins, Specificity, Structure, and Physiology. The Cereal Rusts, Vol. 1. W. R. Bushnell and A. P. Roelfs, eds. Academic Press, Orlando, FL, U.S.A..

Wang, Y., Gao, M., Li, Q., Wang, L., Wang, J., Jeon, J.-S., Qu, N., Zhang, Y., and He, Z. 2008. OsRAR1 and OsSGT1 physically interact and function in rice basal disease resistance. Mol. Plant-Microbe Interact. 21:294-303.

Wiermer, M., Feys, B. J., and Parker, J. E. 2005. Plant immunity: the EDS1 regulatory node. Curr. Opin. Plant Biol. 8:383-389.

Wu, J.-L., Wu, C., Lei, C., Baraoidan, M., Bordeos, A., Madamba, M. Ramos-Pamplona, M., Mauleon, R., Potugal, A., Ulat, V. J., Bruskiewich, R., Wang, G., Leach, J., Khush, G., and Leung, H. 2005. Chemical- and irradiation-induced mutants of indica rice IR64 for forward and reverse genetics. Plant Mol. Biol. 59:85-97.

Wynn, W. K. 1981. Tropic and taxic responses of pathogens to plants. Annu. Rev. Phytopathol. 19:237-255.

Zhao, B., Lin, X., Poland, J., Trick, H., Leach, J., and Hulbert, S. 2005. A maize resistance gene functions against bacterial streak disease in rice. Proc. Natl. Acad. Sci. U.S.A. 102:15383-15388.

Zipfel, C. 2008.. Pattern-recognition receptors in plant innate immunity. Curr. Opin. Immunol. 20:10-16.

\section{AUTHOR-RECOMMENDED INTERNET RESOURCE}

Salk Institute Rice Functional Genomic Express database: signal.salk.edu/cgi-bin/RiceGE 